\title{
DISACCHARIDE INTOLERANCE IN INFANCY
}

\author{
BY \\ NINA A. J. CARSON and R. A. NEELY \\ From the Royal Belfast Hospital for Sick Children, the Dept. of Child Health, Queen's University, Belfast, \\ and the Waveney Hospital, Ballymena
}

(RECEIVED FOR PUBLICATION MAY 20, 1963)

In 1958 Durand published an account of an infant with vomiting and diarrhoea since birth, and he demonstrated the presence of lactose in the urine. Since that time more widespread attention has been paid to sugar intolerance in infants, and an increasing number of reports on such cases have been published.

A survey of the available published material suggests that two forms of this condition exist, which from a clinical and biochemical standpoint show certain distinguishing features.

In the first, diarrhoea is the presenting symptom and the occurrence of vomiting is not stressed: in these cases mellituria occurs but rarely, or not at all; where such studies have been carried out, tolerance curves utilizing the offending sugar have been flat, suggesting impairment of absorption from the intestinal lumen. The diarrhoea in these cases is deemed to be caused by the presence of large quantities of unhydrolysed and unabsorbed sugars in the intestine, and is mediated by osmotic factors or by bacterial action. Characteristically the stools are frothy, strongly acid, and have a high lactic acid content. Such cases have been described by Holzel, Schwarz and Sutcliffe (1959), Durand (1960), Holzel, Mereu and Thomson (1962), Bach, Thiriez, Schaefer and Cayroche (1962), Lindquist and Meeuwisse (1962), Grenet, Lestradet, Dugas, Iniguez and Gourgon (1962).

In the second type, the presenting symptom is intractable vomiting with or without the presence of diarrhoea; mellituria is a prominent feature of these cases and where tolerance curves have been carried out, absorption does not appear to have been impaired. Such cases have been described by Woodruff (1958), Durand (1960), Darling, Mortensen and Søndergaard (1960), Inall (1960), Jeune, Charrat, Cotte, Fournier and Hermier (1960), Heese and Potgieter (1961), Holzel et al. (1962).

In addition to the mellituria an abnormal aminoaciduria has been observed by Darling et al. (1960) and by Heese and Potgieter (1961). Woodruff
(1958) noted the presence of phenylalanine in the urine of one of his cases. On the other hand Inall (1960) did not detect any abnormality in the amino acid pattern. Bach et al. (1962) noted increased amino acid excretion in their case where diarrhoea was the dominant feature and mellituria was not present.

In the present communication we wish to describe three further cases in which vomiting was the predominant symptom and in which mellituria and aminoaciduria were also present.

\section{Technical Methods}

Chromatography of urinary sugars was performed after the method of Smith (1960). Following desalting, $75 \mu \mathrm{l}$. urine were spotted on to a $15 \times 30 \mathrm{~cm}$. strip of Whatman No. 1 chromatography paper on a line drawn $5 \mathrm{~cm}$. from one end, together with $5 \mu 1.0 \cdot 7 \%$ solution (in $10 \%$ isopropanol) of the following sugars; glucose, galactose, sucrose, lactose, fructose and xylose. Glucuronic acid was also included. After 12 hours downward flow in an Aimer chromatography tank using a monophasic solvent composed as follows: n-butanol $120 \mathrm{ml}$.; acetic acid $30 \mathrm{ml}$.; and $\mathrm{H}_{2} \mathrm{O}$ (Dist.) $50 \mathrm{ml}$., the paper was allowed to dry at room temperature and then dipped in a location reagent consisting of the following:

Solution A: benzidine, $1 \mathrm{~g}$. in glacial acetic acid, $40 \mathrm{ml}$; trichloracetic acid, $30 \mathrm{~g}$. and water, $40 \mathrm{ml}$. to one volume.

Solution $B$ : acetone, nine volumes; these two solutions being mixed immediately before use. After dipping in the reagent the chromatogram was developed at a temperature of $100-110^{\circ} \mathrm{C}$. for five minutes, the sugars appearing as dark brown spots on a light yellow background.

Amino acid chromatography was carried out using the 'rack' tank of Datta, Dent and Harris (1950). Total nitrogen estimations were performed on each urine and that volume of urine containing $250 \mu \mathrm{g}$. nitrogen was applied to Whatman's No. 1 chromatography paper. Each urine was desalted before spotting it on to the paper. The solvent system used was butanol-pyridine-water $1: 1: 1$, followed by phenol-ammonia (Smith, 1960).

The amino acids on the developed chromatogram were visualized by dipping in a $0.1 \%$ solution of ninhydrin in 
acetone; they were then dried at room temperature for about 30 minutes and heated at $80^{\circ} \mathrm{C}$. for five to seven minutes.

\section{Case Reports}

Case 1. Baby M. Born January 3, 1961, female, birth weight $6 \mathrm{lb} .12 \mathrm{oz}$. $(3,061 \mathrm{~g}$.). She was the youngest child of healthy, non-consanguineous parents; there were three other children all of whom had progressed normally since birth. At the age of 1 week she was admitted to hospital with a history of vomiting since birth, having been fed with Cow and Gate full-cream milk. A provisional diagnosis of pyloric stenosis was made. At laparotomy, performed on January 12, no evidence of obstruction in any part of the gastro-intestinal tract could be found.

Following operation the vomiting continued and on January 20 , the feeding formula was changed to S.M.A. This change effected some improvement and the child was discharged on February 21 weighing $6 \mathrm{lb}$. $9 \mathrm{oz}$. (2,976 g.). On March 13 she was readmitted with a history of copious vomiting. On examination the child was critically ill, uraemic, and grossly dehydrated, with a pyrexia of $102 \cdot 6^{\circ} \mathrm{F}$. $\left(39 \cdot 2^{\circ} \mathrm{C}\right.$.). Milk feeding, then consisting of National Dried Milk and Ostermilk was discontinued, and parenteral fluid therapy was instituted with sips of glucose and water by mouth.

With correction of the fluid balance the child's condition improved and the blood urea returned to normal. Milk feeding in the form of Ostermilk was reinstituted with immediate reappearance of vomiting. In addition to the routine investigations carried out in the search for a source of infection, faecal fat estimations and serum calcium were performed, which proved to be normal, and a barium meal was given. The radiologist, Dr. D. A. R. Orr, reported that there was a wide cardia with easy oesophageal reflux, but vomiting of most of the barium during the examination made it difficult to be sure whether this was a true hernia or not.

At this stage reducing substances were detected in the urine by 'clinitest', which on chromatography proved to be lactose, sucrose and galactose (Fig. 1). In addition amino acid chromatography showed a gross generalized aminoaciduria (Fig. 2).

In view of the presence of lactose and sucrose in the urine it was decided to exclude these substances from the diet and a mixture was prepared consisting of dextrose and Casilan. On administration of this mixture the vomiting promptly ceased, and within one week the mellituria had disappeared and the aminoaciduria had diminished.

During this time a lactose tolerance test was performed, giving $2 \mathrm{~g}$. lactose per $\mathrm{kg}$. body weight, and this showed a maximal rise of the blood sugar, estimated as total reducing substances, of $39 \mathrm{mg}$. per $100 \mathrm{ml}$., with the reappearance of lactose in the urine.

In spite of the clinical improvement the child's weight continued to fall and by April 2 had fallen to $5 \mathrm{lb} .9 \frac{1}{2} \mathrm{oz}$. $(2,536$ g.). The glucose and Casilan were abandoned and the child was started on Cow and Gate low lactose milk which contains dextrose and dextrin. From that time progress was uninterrupted and normal feeding was

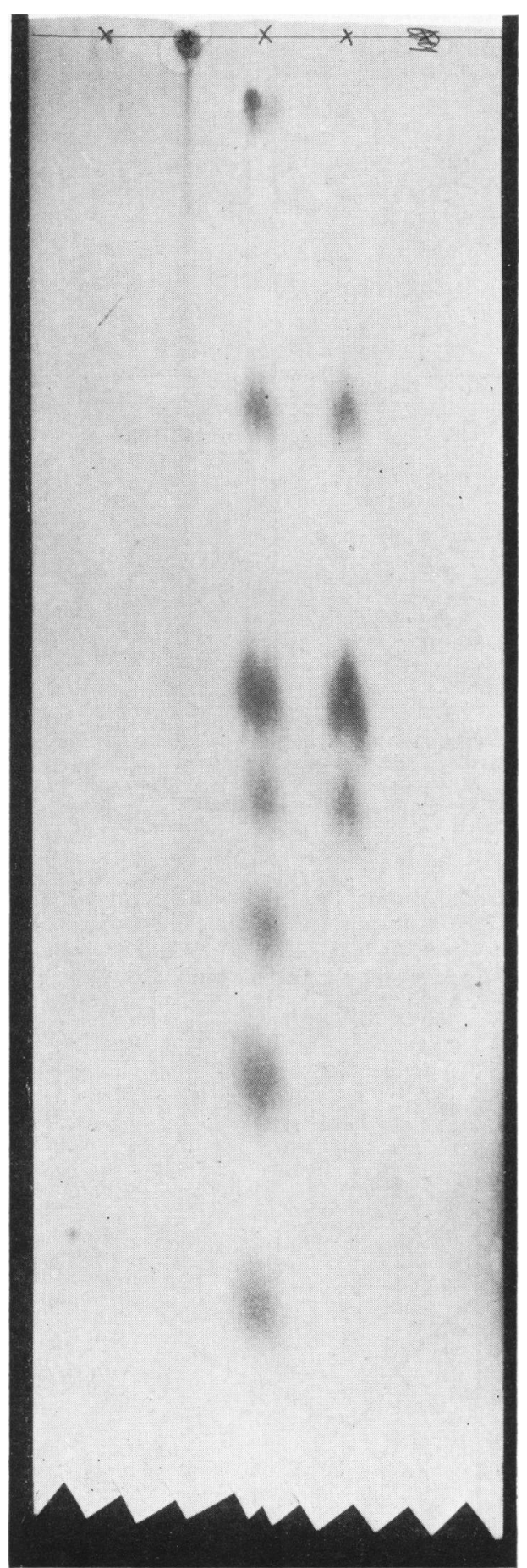

Fig. 1.-One-dimensional sugar chromatogram showing in columns 1, 2, normal urines; (3) glucuronic acid, lactose, sucrose, galactose, glucose, fructose and xylose; (4) urine from Case 1 showing lactose, sucrose and galactose 

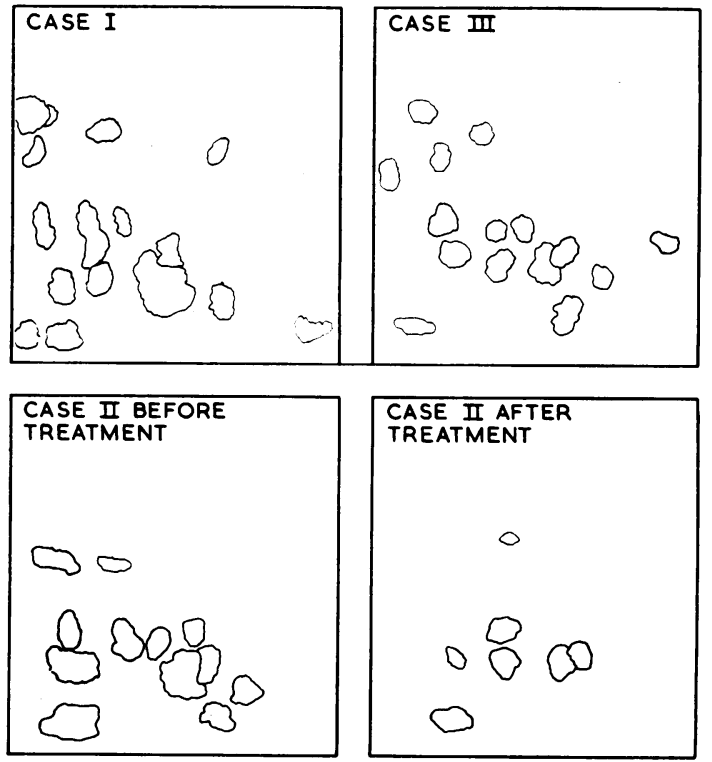

FIG. 2.-Two-dimensional amino acid chromatograms of urines from Cases 1, 2 and 3, showing generalized aminoaciduria, also the decrease in the aminoaciduria in Case 2 following administration of low lactose milk.

commenced during the third week in May. She was discharged from hospital on June 3, at which time her weight was $9 \mathrm{lb} .3 \mathrm{oz}$. (4,167 g.) (Fig. 3). Now, at the age of 2 years, she is a normal healthy child.

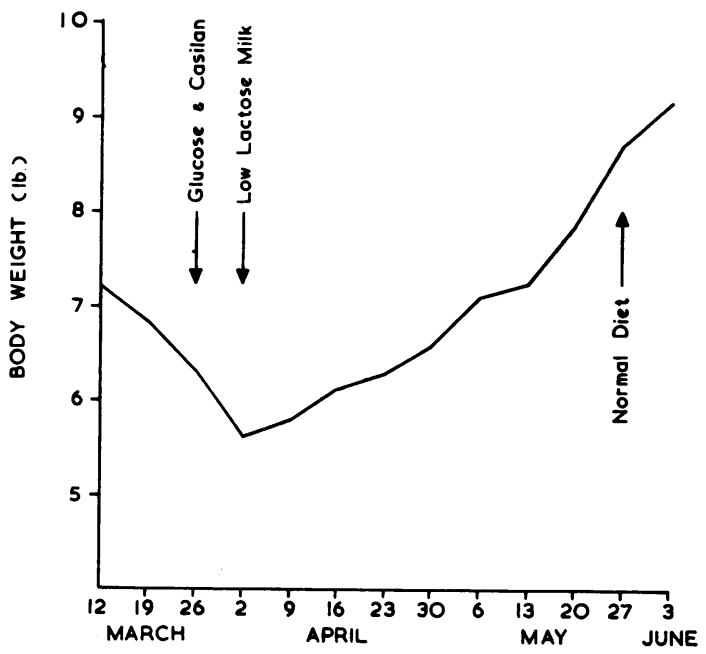

Fig. 3.-Weight chart of Case 1, demonstrating gain in weight on low lactose milk.
Case 2. Baby A. Born September 15, 1962. Female, birth weight $6 \mathrm{lb} .9 \mathrm{oz}$. (2,976 g.). She was the second child of healthy, non-consanguineous parents; the first child had been normal since birth. At the age of 16 days she was admitted to hospital with incessant vomiting, diarrhoea and a low spiking temperature. Weight on admission was $6 \mathrm{lb}$. $4 \mathrm{oz}$. $(2,834 \mathrm{~g}$.) which fell to $6 \mathrm{lb} .2 \mathrm{oz}$. (2,788 g.) during the succeeding two days. She had been breast fed with supplementary feeds of 'ostermilk'.

All routine investigations proved to be negative. The urine contained no detectable reducing substances when tested by 'clinitest', but sugar chromatography revealed lactose, sucrose and galactose. In addition there was a gross generalized aminoaciduria (Fig. 2), of similar pattern to that seen in Case 1.

The infant was started on Cow and Gate low lactose milk, with prompt cessation of the vomiting and diarrhoea, a rapid diminution of the mellituria and aminoaciduria (Fig. 2), and she started to gain weight. One week later it was decided to attempt normal feeding and the child was started once again on 'ostermilk'. Vomiting recommenced immediately and 24 hours later the child was put back on to Cow and Gate low lactose milk. From there on progress was uninterrupted and she was discharged from hospital on October 21, at a weight of $7 \mathrm{lb}$. $(3,175 \mathrm{~g}$.). The low lactose milk was continued at home for a further four weeks and then normal feeding was commenced without incident.

Unfortunately the baby developed an osteomyelitis after discharge from hospital; this responded well to treatment, and now at the age of 7 months the child appears normal.

Case 3. Baby T. Born May 30, 1962, she was one of twins born two weeks prematurely. Birth weight 4 lb. 9 oz. $(1,927$ g. $)$. These were the youngest children of healthy, non-consanguineous parents. There were two other children, $4 \frac{1}{2}$ and 2 years of age, both of whom had been normal since birth.

At the age of 3 days the twin sister died with incessant vomiting. For about the first week Baby $T$. appeared to be feeding well and then she also started to vomit. The vomiting became progressively more severe, and sometimes was of coffee-ground material. There were episodes of pyrexia for which no infective cause could be found, and there was a marked weight loss. A barium meal showed easy oesophageal reflux.

At the age of 13 weeks Benedict's test carried out on the urine showed the presence of reducing substances, and chromatographic examination showed these to be lactose and galactose. In addition there was a mild generalized aminoaciduria of similar pattern to the other cases (Fig. 2). Hepatomegaly was now apparent, and vomiting and weight loss continued to be a problem.

The infant was placed on lactose free milk ('galactomin') which resulted in improvement, although not cessation, of the vomiting and there was a very slow gain in weight. The urine became sugar free, but bouts of pyrexia continued.

This régime was continued for a period of three to four 
weeks, when feeding with Cow and Gate full-cream milk was attempted; this was followed by the reappearance of lactose and galactose in the urine and exacerbation of the vomiting. Cow and Gate low lactose milk was tried next, which resulted in complete cessation of the vomiting, disappearance of the lactose and the galactose from the urine and a slow weight gain. Unfortunately, six days later, the baby contracted a respiratory infection and died within 48 hours, at the age of $4 \frac{1}{2}$ months.

A post-mortem examination was performed by Dr. James Gibson, Lecturer in Pathology at Queen's University, Belfast. This revealed a confluent bronchopneumonia in the left lung. The liver was enlarged and weighed $160 \mathrm{~g}$. It was pale and slightly granular on the surface, and histologically showed a moderate degree of fatty change with an increase in the amount of fibrous tissue which had originated in the portal tracts and which had isolated groups of liver cells in the immediate vicinity. Small, early regenerative nodules were seen and a cirrhotic pattern had arisen although this was not far developed. Large clumps of haemosiderin were seen in macrophages in the portal tracts and in the Kupffer cells. In the kidneys the tubules were not generally dilated, but necrosis of epithelium had occurred in many collecting tubules with the formation of large casts, which were partly extruded and extensively calcified. The appearances were those of a healed lower nephron nephrosis of the type seen in acidotic infarcts. The oesophagus was moderately dilated, and there was a low-grade chronic inflammatory process. No abnormalities were detected in any other portion of the gastrointestinal tract.

\section{Discussion}

Three cases are described in which there was intolerance to disaccharides, and in all of which the predominant symptom was vomiting. In two cases lactose, sucrose and galactose were found in the urine, and in one case lactose and galactose only.

That mellituria does occur in the newborn has been shown by Bickel (1961), who demonstrated glucose, fructose, galactose and lactose in the urine of healthy full-term infants during the first weeks of life, while premature infants tended to show this to a more marked degree. Bickel (1961) does not record the finding of sucrose in these infants, although Smith (1960), Woolf and Norman (1957) and Owen and Lewis (1956) have recorded its occurrence in apparently normal infants. Bickel (1961) postulated that the glucosuria was probably, and the lactosuria was certainly, of prerenal origin, most probably being due to a deficiency of lactase and to an increased permeability of the intestinal mucosa of the newborn infant.

Dahlqvist (1962) has investigated the specificity of the human intestinal disaccharidases, and has indicated the nature of the intolerance resulting from a deficiency of each of them. In the light of his findings we consider Cases 1 and 2 to be the result of a deficiency of invertase (maltase $I$ b) and lactase, and Case 3 to be a deficiency of lactase. We also consider that these deficiencies exist in the presence of a normal absorptive capacity of the intestinal mucosa, with resultant mellituria and presenting a normal lactose tolerance curve according to the criteria of Weijers, Kamer, Dicke and Ijsseling (1961).

Holzel et al. (1962), on the other hand, consider the passage of unsplit lactose through the mucosa to be due to damage of the mucosa by lactose, thereby interfering with the absorptive capacity of the intestine.

It is thought that the intractable vomiting, a feature of these cases, is due to a 'toxic' action of the circulating unhydrolysed disaccharide.

These findings are in contradistinction to the other group of cases, of similar aetiology, in which there is failure to absorb the unhydrolysed sugars, as evidenced by a flat tolerance curve and in which the dominant symptom is diarrhoea, with mellituria seldom appearing.

Of the presently reported cases both children who survived were able to resume normal feeding without incident after approximately six weeks on the Cow and Gate low lactose milk. A similar restoration to normal in eight to 10 weeks has been noted by Holzel et al. (1962), in five to 10 weeks by Inall (1960) and after an unspecified period in one case by Woodruff (1958). These experiences suggest that this disorder is transient. On the other hand, case mortality is high, and of the seven reported cases studied, five have died, as did one of our own. In our case the most striking changes at autopsy were seen in the liver and the kidneys.

The abnormal amino acid excretion seen in these cases may be of a secondary nature, as suggested by Darling et al. (1960). It is considered that this is similar in nature to the reversible aminoaciduria seen in galactosaemia and which is due to renal tubular damage resulting in a defect in the transfer and reabsorption of amino acids across the renal tubule.

Since a similar condition has been described in siblings of affected cases, and has been found in children of consanguineous marriages, a hereditary basis has been suggested for its occurrence. Darling et al. (1960) and Heese and Potgieter (1961) have carried out studies on near relatives of their patients with failure to demonstrate any abnormality.

In view of the occurrence of mellituria in otherwise healthy infants, and in consideration of the transient nature of the condition in at least some of these cases, it is tempting to regard any deficiency as a temporary one, and to represent it as a delay in the 
development of one or more of the intestinal disaccharidases.

It is important that the condition be suspected in cases of persistent vomiting in infancy, and it should be realized that the commonly used reduction tests for the detection of sugar in urine are nonspecific and may be too insensitive to be relied upon for diagnosis. Urinary sugar chromatography and amino acid chromatography should be performed in all suspect cases.

\section{Summary}

Three cases of disaccharide intolerance in infancy are described; one died at the age of $4 \frac{1}{2}$ months. In all three the presenting symptom was intractable vomiting. In two cases lactose, sucrose and galactose were demonstrated in the urine by chromatography, and in the other lactose and galactose. All three showed a gross aminoaciduria.

The pathogenesis is discussed and the unreliability as an aid to diagnosis of the standard method for the detection of reducing substances in the urine is stressed.

Our thanks are due to Dr. R. J. Young, Department of Paediatrics, Londonderry City and County Hospital, who referred Case 3. To Professor F. M. B. Allen, Nuffield Professor of Child Health at the Royal Belfast Hospital for Sick Children, and to Dr. R. J. Kernohan, Physician at the Waveney Hospital, Ballymena, for their permission to investigate and report on the cases in their charge.

\section{REFERENCES}

Bach, Ch., Thiriez, H., Schaefer, Ph. and Cayroche, P. (1962). Intolérance au saccharose chez un nourrisson. Arch. franc. Pédiat., 19, 1138

Bickel, H. (1961). Mellituria, a paper chromatographic study. J. Pediat., 59, 641.

Dahlqvist, A. (1962). Specificity of the human intestinal disaccharidases and implications for hereditary disaccharide intolerance. J. clin. Invest., 41, 463 .

Darling, S., Mortensen, O. and Søndergaard, G. (1960). Lactosuria and amino-aciduria in infancy. Acta paediat. (Uppsala), 49,281 .

Datta, S. P., Dent, C. E. and Harris, H. (1950). An apparatus for the simultaneous production of many 2-dimensional paper chromatograms. Science, 112, 621 .

Durand, P. (1958). Lattosuria idiopatica in una paziente con diarrea cronica ed acidosi. Minerva pediat., 10, 706.

Grenet (1960). Intolérance au lactose. Pédiatrie, 15, 407 . (1962). Lestradet, H., Dugas, M., Iniguez, $\mathbf{M}$. and Gourgon, $\mathbf{R}$. chez un nourrison. Arch. franc. Pédiat., 19, 1131

Heese, H. de V. and Potgieter, G. M. (1961). Lactosuria and aminoaciduria in infancy. S. Afr. med. J., 35, 489.

Holzel, A., Mereu, T. and Thomson, M. L. (1962). Severe lactose intolerance in infancy. Lancet, 2,1346

, Schwarz, V. and Sutcliffe, K. W. (1959). Defective lactose absorbtion causing malnutrition in infancy. ibid., 1, 1126.

Inall, J. A. (1960). Lactosuria and sucrosuria with failure to thrive. Proc. roy. Soc. Med., 53, 318 .

Jeune, M., Charrat, A., Cotte, J., Fournier, P. and Hermier, M. (1960). Sur un cas de lactosurie congénitale. Pédiatrie, 15, 411.

Lindquist, B. and Meeuwisse, G. W. (1962). Chronic diarrhoea caused by monosaccharide malabsorbtion. Acta paediat. (Uppsala), $51,674$.

Owen, J. A. and Lewis, I. C. (1956). Sucrosuria in children. Scot. med. J., 1, 231.

Smith, I. (1960). Chromatographic and Electrophoretic Techniques, 2nd ed., vol. 1. Heinemann, London.

Weijers, H. A., Kamer, J. H. van de, Dicke, W. K. and Ijsseling, J. (1961). Diarrhoea caused by deficiency of sugar splitting enzymes. I. Acta paediat. (Uppsala), 50, 55.

Woodruff, G. G. (1958). Sucrosuria in association with mental deficiency and hiatal hernia. J. Pediat., 52, 66.

Woolf, L. I. and Norman, A. P. (1957). The urinary excretion of amino acids and sugars in early infancy. ibid., 50, 271. 